\title{
Comparison between one stage operation for obstructed left colon cancer and Hartmann's procedure
}

\author{
Mohammad M Ali, MD; Hosam F Abdelhameed, $M D$; \\ Samir A abdelmegeed, $M D$
}

Department of General Surgery, Sohag University Hospital, Egypt.

\begin{abstract}
Background: Although acute obstruction of the right colon is usually dealt with by primary anastomosis following resection, many surgeons are reluctant to offer one stage resection and anastomosis to patients with obstructive lesions of the left colon.

Aim: The aim of the study is to compare the result of one stage resection and anastomosis for patients with acute complete obstruction due to left colon cancer versus Hartman's procedure.

Patients and methods: Eighty four patients with acute left colonic obstruction presented to Sohag University Hospital between march 2008 and February 2012. The diagnosis was based on clinical evidence of obstruction and radiological features of left colonic obstruction on plain $x$-ray abdomen. No pre-operative histopathological confirmation of the diagnosis was done for all patients. Thirty eight patients were managed by one stage left colectomy without intraoperative lavage (only manual evacuation of colon and mobbing of the two ends of anastomosis). Hartmann's procedure was performed in thirty four patients. Twelve patients were excluded from the study according to the following criteria: 1-patients with inoperaple tumors (liver metastasis, peritoneal seedling, haemorrhagic ascitis or unresectable). 2-medically unfit or haemodynamiclly unstable patients . 3-colonic perforation or peritonitis.

Results: As regards the post operative complications related to left sided colonic surgery (wound sepsis, intra-peritoneal sepsis, anastomotic leakage), there were no significant difference between the two techniques.
\end{abstract}

\section{Introduction:}

Colorectal cancer is common in developed countries and about $15 \%-20 \%$ of patients present with an intestinal obstruction needing emergency surgery. ${ }^{1,2}$ Obstructing tumors are generally more advanced, with a higher incidence of local extension and distant metastasis than non-obstructing neoplasmes. Also emergency surgery on a distended and unprepared bowel in high risk patients results in high morbidity and mortality rates. ${ }^{3}$

Until recently, the obstructing left sided colonic lesions were traditionally managed by either three stage surgery, consisting of diverting colostomy, colonic resection and colostomy closure ${ }^{4}$ or two stage surgery; consisting of resection with proximal colostomy or Hartman's procedure followed by later reconstruction. 5,6

Nowadays, there are surgical techniques that allow colonic resection and reconstruction to be performed in a single stage procedure, consisting of resection and primary anatomists with or without intraoperative colonic irrigation. ${ }^{7-11}$ One of the most advantage of this type of procedure is that it eliminates the need for temporary stoma. In our hospital, emergency surgery for obstructed colorectal cancer is carried out by general surgeons, and the techniques used for resection are therefore dependent on the attending surgeon's experience and the patient's specific condition. In our study we compared and analyzed the results of two different techniques to determine if single stage procedure (without intra-operative 
lavage) is associated with higher post operative morbidity and consumption of resources than the more conservative Hartman's technique.

\section{Patients and methods:}

Eighty four patients with acute left colonic obstruction presented to Sohag University Hospital between march 2008 and February 2012. The diagnosis was based on clinical evidence of obstruction and radiological features of left colonic obstruction on plain x-ray abdomen. No preoperative histopathological confirmation of the diagnosis was done for all patients. Thirty eight patients were managed by one stage left colectomy without intra-operative lavage (only manual evacuation of colon and mobbing of the two ends of anastomosis). Hartman's procedure was performed in thirty four patients. Twelve patients were excluded from the study according to the following criteria: 1- patients with inoperaple tumors (liver metastasis, peritoneal seedling, haemorrhagic ascitis or unresectable). 2- medically unfit or haemodynamically unstable patients. 3- colonic perforation or peritonitis.

\section{Results:}

There were eighty four patients with acutely obstructive carcinomas that required emergency surgery. Only seventy two patients were included in the study. There were forty six men and twenty sex women with mean age of 61.8 years old (ranging from 38-83 years). The demographic data of the patients who had tumors at left side of colon and underwent one stage and two stage operation were shown in Table(1).

The tumors of both groups were mainly in Duke C (26/34 patients or $76.4 \%$ in two stage group and $32 / 38$ or $84.2 \%$ in one stage operation group).

As regards tumor histology, there was no difference in both groups except the higher number of tumor with poor differentiation in two stage group.

Sites of tumors in one stage group were mainly in proximal descending colon and proximal sigmoid colon $(26 / 38$ patients or $68.3 \%$ ) while most tumors in the two stage operation were in distal sigmoid colon and rectosegmoid area (30/34 patient or $88.2 \%$ ). All patients of one stage group underwent immediate primary colonic anatomists without colostomy after resection and without intraoperative lavage (only manual evacuation of the proximal distended colon and cleaning of the two ends of anatomists with saline wet gauzes). In the two stage group, Hartmann's operation was done Table(2).

There was no statistical difference in wound sepsis, intra-operative sepsis, anastomotic leakage and thirty days mortality in both groups after the operations Table(3).

\section{Table (1): The demographic data of patients.}

\begin{tabular}{|cl|c|c|c|}
\hline \multicolumn{2}{|c|}{ Characteristics of patients } & $\begin{array}{c}\text { One stage group } \\
\mathrm{N}=38\end{array}$ & $\begin{array}{c}\text { Two stage group } \\
\mathrm{N}=34\end{array}$ & P value \\
\hline Gender & male & 26 & 20 & 0.75 \\
& female & 12 & 14 & \\
\hline Median age & $61.8(38-83$ & $61.5(48-76)$ & \\
\hline Duck stage & $\mathrm{A}$ & 0 & 0 & \multirow{2}{*}{0.79} \\
$\mathrm{~B}$ & $3(7.9 \%)$ & $4(11.8 \%)$ & \\
$\mathrm{C}$ & $32(84.5 \%)$ & $26(67.4 \%)$ & \\
$\mathrm{D}$ & $3(7.9 \%)$ & $2(11.8 \%)$ & \\
\hline Histological differentiation & & & \\
& & $2(8.9 \%)$ & \\
well & $6(15.6 \%)$ & $14(41.1 \%)$ & \\
moderate & $19(50 \%)$ & $18(52 \%)$ & \\
poor & $13(34.2 \%)$ & &
\end{tabular}


Table(2): Site of tumors in one stage group and two stage group.

\begin{tabular}{|l|c|c|c|}
\hline $\begin{array}{l}\text { Characteristics of } \\
\text { patients }\end{array}$ & $\begin{array}{c}\text { One stage group } \\
\mathrm{N}=38\end{array}$ & $\begin{array}{c}\text { Two stage group } \\
\mathrm{N}=34\end{array}$ & P value \\
\hline Site of tumors & $15(39.5 \%)$ & & \\
Descending colon & $11(28.9 \%)$ & $4(11.8 \%)$ & \\
Proximal sigmoid & $6(17 \%)$ & $12(35.4 \%)$ & \\
Distal sigmoid & $6(17 \%)$ & $18(52.9 \%)$ & \\
rectosigmod & & \\
\hline
\end{tabular}

Table (3):

\begin{tabular}{|l|c|c|c|}
\hline Morbidity\&mortality & $\begin{array}{c}\text { One stage group } \\
\mathrm{N}=38\end{array}$ & $\begin{array}{c}\text { Two stage group } \\
\mathrm{N}=34\end{array}$ & P value \\
\hline Wound sepsis & $6(15.7 \%)$ & $4(11.8 \%)$ & 0.52 \\
Intra operative sepsis & $3(7.9 \%)$ & $2(5.4 \%)$ & 0.63 \\
Anastigmatic leakage & $2(5.3 \%)$ & 0 & 0.47 \\
Colostomy necrosis & 0 & $3(10.2 \%)$ & \\
Death & $3(7.9 \%)$ & $4(11.8 \%)$ & 0.49 \\
\hline
\end{tabular}

\section{Discussion:}

The choice of treatment for obstructed carcinomas of left sided colon is still debated because of its high associated morbidity and mortality and the number of different surgical options available.1,2 Some times the patient's local or general condition can simplify the decision making process. Most patients with a very high surgical risk or unresectable neoplasms will be treated with decompressive colostomy, whereas coecal ischemia and perforation or synchronus tumors in the right colon are strong indication for subtotal colectomy. On the other hand, subtotal colectomy is contraindicated in patients with pre-operative sphencteric dysfunction. ${ }^{3,4}$ The attending surgeon may decide to delay the surgery, trying to carry out an intestinal preparation, with or without the placement of a self-expanding endoluminal prothesis to allow colonic resection on an elective basis. ${ }^{12-14}$ On the other hand in an emergency operation the surgeon may decide on Hartman's procedure, single stage subtotal colectomy, or colectomy with primary anatomosis (CPA) with or without intra operative colonic irrigation. .-11 $^{-11}$

The post operative morbidity after surgery for malignant left sided colonic obstruction is high $8,11,13$ being about (43\%) in many series and the complications such as anastomotic leakage and post operative infections were mainly related to the surgical technique used.

Although the incidence of complications after colectomy and primary anastomosis with intra-operative lavage was lower than that after other techniques, the difference was not significant.

In our study, the post operative mortality was $7.9 \%$ in one stage group and $11.8 \%$ in Hartman's procedure and this came in accordance with that of other recent series ranging from 2\%-12\%.1,3,8,13 Anastomotic leakage affected (5.3\%) of patiens who underwent primary anastomosis without intra-operative lavage which is in accordance with that reported in literatures with segmental resection and primary anastomosis with intra-operative colonic irrigation and total or subtotal colectomy while anastomotic leakage is avoided in Hartmann's procedure but it is associated with short-term complicatins such as colostomy necrosis which occurred in $(10.2 \%)$ in our study. Moreover the creation of a stoma has obvious reprecussion on the patient's quality 
of life, psychological status and economic situation. Wound sepsis occurred in $(15.7 \%)$ none stage group compared with $(11.8 \%)$ in hartmann's procedure which is statistically insignificant $(\mathrm{p}=0.52)$. Intraperitoneal sepsis occurred in $(7.9 \%)$ in one stage group and in $(5.9 \%)$ in Hartmann's procedure which is statistically insignificant $(\mathrm{p}=0.63)$. In conclusion there was no statistical difference as regards wound sepsis, intra-operative sepsis, anastomotic leakage and thirty days mortality in both groups.

\section{Conclusion:}

Although one stage approach for obstructive carcinoma of left colon limits in selected patients and may take longer time for operation, the study supports that one stage approach had similar outcome as Hartmann's procedure with the advantage of avoidance the risk of second operation, saving time for waiting for second operation in addition to avoidance the troubles of temporary colostomy.

\section{References:}

1- Lee YM, Law WL, Chu KW, Poon RT: Emergency surgery for obstructing colorectal cancers: A comparison between right-sided and left-sided lesions. $J \mathrm{Am}$ Coll Surg 2001; 192: 719-725.

2- Lopez-kostner F, Hool GR, Lavery IC: Management and causes of acute largebowel obstruction. Surg Clin North AM 1997; 77: 1265-1290.

3- Runkel NS, Hinz U, Lehnert T, Buhr HJ, Herfarth C: Improved out come after emergency surgery for cancer of the large intestine. Br J Surg 1998; 85: 1260-1265.

4- Goligher JC: Surgey of the anus, rectum and colon. London: Ballie're Tindall (Publisher); 5th edn.; 1986; 542-558.

5- Cugnce $\mathrm{PH}$, bereger A, zinzindohoue $\mathrm{F}$, quinux $\mathrm{D}$, wind $\mathrm{P}$, chevalier JM: 2-stage surgery of neoplastic left colonic obstruction remains the safest procedure. $J$ Chir 1997; 134: 275-278.
6- Chua Cl: Surgical consideration in the Hartmann's procedure. Aust NZJ Surg 1996; 66: 676-679.

7- Dudiey HA, Radcliffe AG, McGeehan $D$ : Intraoperative irrigation of the colon to permit primary anastonosis. $\mathrm{Br} J$ Surg 1980; 67: 80-81.

8- Turn M, Ok E, Sen M, koyuncu A, Ayden C, Erdem M, et al: A simplified operative technique for single staged resection of left sided colon obstruction: Report of a 9-years experience. Surg Today; 2002; 32: 959-964.

9- Omejc M, Stor Z, Jelenc F, Repse S: Outcome after emergency subtotal/total colectomy compared to elective resection in patients with left sided colorectal carcinoma. Int Surg 1998; 83: 241-244.

10-Rralba JA, Robles R, Parrilla p, Lujan JA, Liron R, Pinero A, et al: Subtotal colectomy vs intraoperative colonic irrigation in the management of obstructed left colon carcinoma. Dis colon rectum 1998; 41: $18-22$

11-Arnaud JP, Tuech JJ, Duplessis R, pessaux $P$ : Role of subtotal /total colectomy in emergency treatment of occlusive cancer of the left colon. Ann Chir 1999; 53: 1019-1022.

12-Mainar A, De Gregorio MA, Tejero E, Tobio R, Alfonso E, Pinto I, et al: Acute colorectal obstruction: Treatment with self-expandable metallic stents before scheduled surgery - results of a multicenter study. Radiology 1999; 210: 65-69.

13-Tack J, Gevers AM, Rutgeerts P: Selfexpandable metallic stents in the palliation of rectosigmoidal carcinoma: A followup study. Gastrointest Endosc 1998; 48: 267-271.

14-Arnel T, Stamos MJ, Takahashi P, ojha S, Sze G, Eysselein V: Colonic stents in colorectal obstruction. Am Surg 1998; 64: 986-988. 